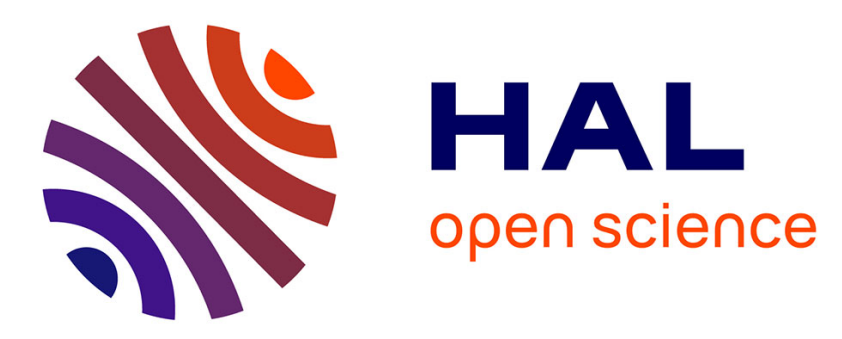

\title{
Toward the Design of Multi Asymmetric Surface Dielectric Barrier Discharge (ASDBD) Actuators
}

Massiel Zadeh, Vandad-Julien Rohani, François Cauneau, Frédéric Fabry, Laurent Fulcheri

\section{- To cite this version:}

Massiel Zadeh, Vandad-Julien Rohani, François Cauneau, Frédéric Fabry, Laurent Fulcheri. Toward the Design of Multi Asymmetric Surface Dielectric Barrier Discharge (ASDBD) Actuators. 13th High-Tech Plasma Processes Conference, Jun 2014, Toulouse, France. pp.Article number 012041, 10.1088/1742-6596/550/1/012041 . hal-01058080

HAL Id: hal-01058080

https://hal-mines-paristech.archives-ouvertes.fr/hal-01058080

Submitted on 26 Aug 2014

HAL is a multi-disciplinary open access archive for the deposit and dissemination of scientific research documents, whether they are published or not. The documents may come from teaching and research institutions in France or abroad, or from public or private research centers.
L'archive ouverte pluridisciplinaire $\mathbf{H A L}$, est destinée au dépôt et à la diffusion de documents scientifiques de niveau recherche, publiés ou non, émanant des établissements d'enseignement et de recherche français ou étrangers, des laboratoires publics ou privés. 


\title{
Toward the Design of Multi Asymmetric Surface Dielectric Barrier Discharge (ASDBD) Actuators
}

\author{
M Zadeh, V Rohani, F Cauneau, F Fabry, L Fulcheri \\ Centre for Processes, Renewable Energies and Energy Systems - PERSEE - \\ MINES ParisTech, CS 10207 rue Claude Daunesse, 06904 Sophia Antipolis \\ Cedex, France \\ E-mail: massiel.zadeh@mines-paristech.fr
}

\begin{abstract}
This paper investigates the electrical behaviors of a single-ASDBD actuator and a two-ASDBD one supplied in sinusoidal mode (1-10 kHz). The main objective of our research is to determine the optimum frequency values for functioning of these actuators with a given power supply. For that purpose, we determine the electrical power density input to the actuators versus frequency through two methods: i) a theoretical method, based on an impedance calculation, and ii) an experimental method, based on direct electrical measurements. These methods show that the addition of a second ASDBD changes the resonance frequency value of the actuator by moving it towards the low frequencies.
\end{abstract}

\section{Introduction}

Surface Dielectric Barrier Discharges (SDBD), such as those firstly introduced by Roth et al. [1], have been studied for ten years, and used for the design of electrohydrodynamic (EHD) actuators [2-4]. The advantages of such actuators are their geometrical flexibility and their quasiinstantaneous response due to the absence of moving solid elements, two qualities highly sought for the development of air flow control systems.

When an ASDBD is supplied in AC sinusoidal mode with high-voltage amplitudes, plasma can be formed in the inter-electrode air gap. The formation of plasma gives rise to an effective body force on the ambient air resulting from the momentum exchange between the drifted charges produced in the plasma and the neutral air molecules. This force can be introduced in the NavierStockes proportional to the electric field [5-6]:

$\mathbf{f} \propto\left(\rho_{+}-\rho_{-}\right) \mathbf{E}$

Where $\rho_{+}$and $\rho_{-}$are the positive and negative charge mass densities respectively, and $\mathbf{E}$ is the electric field. Although the direction of the charge transfer varies during an AC cycle of supply, the body force always has the same direction.

Nowadays, different approaches are used to increase the performance of SDBD actuators, i.e. the miniaturization [6], specific barrier materials [7, 8], the optimization of supply signal form [9] and the pressure measurements [10]. The optimization of an ASDBD actuator needs to couple the 
methods coming from electrical engineer and plasma physics. Some researchers [11, 12] have studied the quantification of the power consumption in function of frequency for a range of voltage and frequency values and a specific ASDBD experimental setup. Kreigseis et al [12] have worked with the range of low frequencies $(<1 \mathrm{kHz})$ and high voltage $(>10 \mathrm{KV})$. They have deduced that for a constant voltage value, the power per unit length increases with frequency.

The major goal of our work is to acquire a better understanding of the electrical behavior of elementary ASDBD actuators as to look forward designing a multi-ASDBD actuator which will have a high electro-mechanical conversion yield. The electrical study, consisting on a characterization of the actuators frequency response, is performed by the determination of the electrical power density input to the actuators. For that, we calculate the electrical input power density versus the applied frequency via two methods: i) a theoretical method, based on the calculation of the actuators total impedance coupled to only voltage measurements and ii) an experimental method, based on direct measurements of voltage and current. All the experiments are operated in the following electrical conditions: i) $1<$ voltage $<10 \mathrm{kV}$ and ii) $1<$ frequency $<10 \mathrm{kHz}$. In our case, we want to determine the law of dependence between the electrical power density and the frequency. The power supply used in our study is a resonant one which implicates the determination of the resonance frequency of the system that increases the transferred power to the discharge.

\section{Experimental setup}

The ASDBD used in our studied actuators are composed of passive and active electrodes separated by a dielectric barrier material, as shown in Figure 1. The electrode arrangement consists of an exposed passive electrode placed on the upper side of the dielectric barrier and an active electrode located below the dielectric barrier.

The passive electrode is connected to a shunt resistor and to the ground while the active electrode is linked to an AC power supply delivering a sinusoidal waveform. The surface plasma is created only on the passive electrode side. The dielectric plate made of borosilicate glass $\left(\varepsilon_{\mathrm{r}}=4.6\right)$ with a thickness of $1 \mathrm{~mm}$, has a section equal to $150 \times 150 \mathrm{~mm}^{2}$. We have chosen the Borosilicate for its two important properties: i) rigidity and ii) resistance to thermal shock. High-Voltage (HV) and ground electrodes are made of aluminum strips $\left(\sigma=37.7 \times 10^{6} \mathrm{~S}^{\mathrm{m}} \mathrm{m}^{-1}\right)$ with a thickness of $50 \mu \mathrm{m}$, length of $110 \mathrm{~mm}$ and a width of $5 \mathrm{~mm}$ and $1 \mathrm{~mm}$, respectively.

We can divide the AC power supply into two parts: i) a primary part composed of an amplified signal generator and a transformer's primary, ii) a secondary part composed of the transformer's secondary (max: x100). As for all transformers, the transformation rate of our transformer depends on the signal frequency value. The high-voltage obtained in the secondary part is measured with a HV probe. The electric current $\mathrm{I}(\mathrm{t})$ streaming into the system is measured with a shunt resistor of $100 \Omega$. The evolution of the applied voltage waveform and the corresponding discharge current are visualized and recorded on an oscilloscope (Agilent Technologies DSO1002A, Bandwidth $60 \mathrm{MHz}, 2 \mathrm{GS} / \mathrm{S}$ and 20kpts/CH). The electrical power input is deduced from the measurements of $\mathrm{U}(\mathrm{t})$ (i.e. the potential difference between the electrodes) and the discharge current $I(t)$. 
As illustrated in Figure 1, the two-ASDBD actuator is composed of two ASDBD's placed one behind the other. We present the electrical measurements on both configurations in order to deduce the electrical power density input to the actuators by theoretical and experimental procedures.

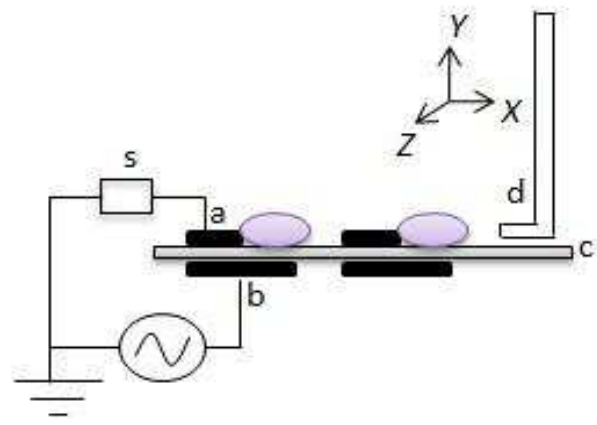

Figure 1. Schematic view of the experimental setup of the single and two-ASDBD actuators: a: ground electrode; b: HV electrode; c: dielectric barrier; d: Pitot probe; s: shunt resistor.

\section{Electrical behavior study}

This section presents the electrical behavior study of a single-ASDBD actuator and a twoASDBD one. This study deals with two dependent segments. The first segment determines the resonance frequency for both actuators by a theoretical method. This is achieved by studying the equivalent circuit model of the system and by coupling the calculation of the actuators total impedance and the RMS voltage measurements. The second segment characterizes experimentally the response frequency of the actuators supplied by the power supply.

We describe this method in the following section which is achieved by determining the electrical power input density to the electrodes via voltage and current measurements at actuators terminals. Note that all electrical experiments are made for an applied rms voltage fixed at $20 \mathrm{~V}$ in the primary part of the power supply.

a.

\section{heoretical method}

In agreement with Enloe et al. works [10, 13], the equivalent circuit model of the electrical system is illustrated in Figure 2. The circuit includes: i) the transformer's secondary and, ii) the ASDBD actuator. The transformer's secondary is composed of its inductance $\left(\mathrm{L}_{\mathrm{II}}\right)$ and resistance $\left(\mathrm{R}_{\mathrm{II}}\right)$ which are measured experimentally and are equal to approximately $20 \mathrm{H}$ and $3.73 \mathrm{k} \Omega$, respectively. The ASDBD actuator is modeled by the association of: a gas capacitance $\left(\mathrm{C}_{\mathrm{g}}\right)$, a plasma resistance $\left(R_{p}\right)$ and dielectric barrier capacitances $\left(C_{d}, C_{d}\right)$. The plasma resistance is a time variable quantity and is estimated by an integral calculation using the measured voltage and current. $C_{g}, C_{d}$ and $C_{d}$ are calculated by following the expressions (2), (3) and (4). They depend on the geometry of the electrodes, the thickness of the air gap (for $\mathrm{C}_{\mathrm{g}}$ ) and the thickness of the dielectric barrier (for $\mathrm{C}_{\mathrm{d}}$ and $\mathrm{C}_{\mathrm{d}^{\prime}}$ ). $\mathrm{C}_{\mathrm{d}}$, depends on the electrode overlap width $\left(\mathrm{l}_{1}\right)$ while $\mathrm{C}_{\mathrm{d}}$ and $\mathrm{C}_{\mathrm{g}}$ 
depend on the air gap width $\left(l_{2}\right)$ as illustrated in Figure 3. All these capacitances are also dependent on the added number of ASDBD.

a)

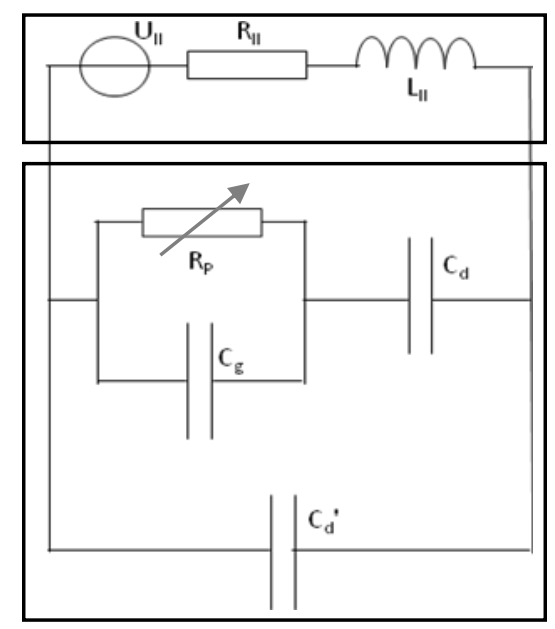

Figure 2. Equivalent circuit model of an ASDBD actuator (b) with a part of its power supply (a)

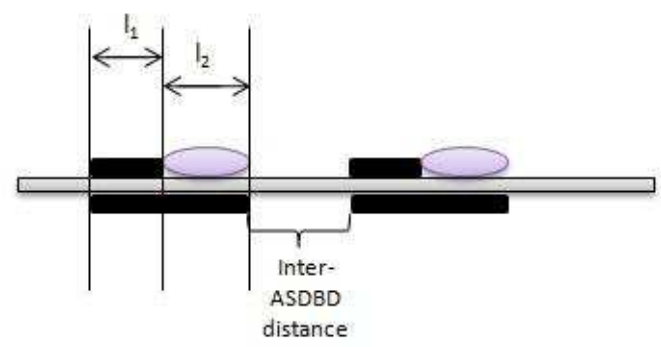

Figure 3. Scheme of the two-ASDBD actuator showing the difference between the electrode overlap width $\left(\mathrm{l}_{1}\right)$ and the air gap width $\left(l_{2}\right)$

$$
\begin{aligned}
C_{g} & =\frac{N \varepsilon_{0} \varepsilon_{r}^{g} S_{2}}{e_{g}} \\
C_{d} & =\frac{N \varepsilon_{0} \varepsilon_{r}^{d} S_{2}}{e_{d}} \\
C_{d^{\prime}} & =\frac{N \varepsilon_{0} \varepsilon_{r}^{d} S_{1}}{e_{d}}
\end{aligned}
$$

Where $\mathrm{N}$ is the ASDBD number of the actuator, $\varepsilon_{0}$ the vacuum permittivity $\left(=8.85 \times 10^{-12} \mathrm{~F} \cdot \mathrm{m}^{-1}\right)$, $\varepsilon_{r}^{g} \quad(=1)$ and $\varepsilon_{r}^{d}(=4.6)$ the relative dielectric permittivity's of air and dielectric barrier respectively, $S_{1}$ the electrode overlap surface equal to the product of the length $\left(\mathrm{L}_{\mathrm{e}}\right)$ and the electrode overlap width $\left(l_{1}\right)$ in $\mathrm{m}^{2}, \mathrm{~S}_{2}$ the air gap surface equal to the product of the length $\left(\mathrm{L}_{\mathrm{e}}\right)$ 
and the air gap width $\left(\mathrm{l}_{2}\right)$ in $\mathrm{m}^{2}, \mathrm{e}_{\mathrm{d}}$ the thickness of the dielectric barrier in $\mathrm{m}$ and $\mathrm{e}_{\mathrm{g}}$ the thickness of plasma following the $z$ direction in $\mathrm{m}$. The thickness of plasma is considered equal to the thickness of the boundary layer.

As illustrated in Figure 2 the gas capacitance $\left(C_{g}\right)$ and its resistance $\left(R_{p}\right)$ are placed in parallel in the equivalent circuit model. The resulting impedance of these two components is added to the impedance of the first part of dielectric barrier (which the capacitance is $\mathrm{C}_{\mathrm{d}}$ ) and is written as:

$Z_{2}(f)=\frac{1+j 2 \pi \cdot f \cdot R_{p}\left(C_{d}+C_{g}\right)}{-4 \pi^{2} f^{2} R_{p} C_{d} C_{g}+j 2 \pi \cdot f \cdot C_{d}}$

$\mathrm{Z}_{2}(f)$ is in parallel with $\mathrm{Z}_{1}(f)$, the impedance of the sandwiched part of the dielectric barrier (which the capacitance is $\mathrm{C}_{\mathrm{d}^{\prime}}$ ). Each term related to the equivalent circuit model of the actuators is calculated separately, leading to the determination of the actuators total impedance, as detailed in the expression (6):

$Z_{a}(f)=\frac{1+j 2 \pi \cdot f \cdot R_{p}\left(C_{d}+C_{g}\right)}{-4\left(C_{d} \cdot R_{p}\left(C_{d}+C_{g}\right)+R_{p} C_{d} C_{g}\right) f^{2} \pi^{2}+j 2 \pi \cdot f \cdot\left(C_{d}+C_{d^{\prime}}\right)}$

By establishing the equivalent circuit model and calculating the actuators total impedance, we worked out the resonance frequency of the single-ASDBD and two-ASDBD actuators. Here we considered that the ratio between the root mean square of the voltage measured for a given frequency and $\mathrm{Z}_{\mathrm{a}}(f)$ calculated for the same frequency, was equal to the electrical power density $p_{e}$ input to the electrodes (i.e. input electrical power per unit of electrode length) as:

$$
p_{e}\left(W / c m_{e}\right)=\frac{U_{r m s}^{2} \operatorname{Re}\left[Z_{a}(f)\right]}{N \cdot L_{e} \cdot\left(\operatorname{Re}\left[Z_{a}(f)\right]^{2}+\operatorname{Im}\left[Z_{a}(f)\right]^{2}\right)}
$$

Where $U_{r m s}^{2}$ is the root mean square of the measured rms voltage in $\mathrm{kV}, \mathrm{N}$ the number of ASDBD composing the actuator, $\mathrm{L}_{\mathrm{e}}$ the electrode length in $\mathrm{cm}, \operatorname{Re}\left[\underline{\mathrm{Z}}_{\mathrm{a}}(f)\right]$ and $\operatorname{Im}\left[\underline{\mathrm{Z}}_{\mathrm{a}}(f)\right]$ are the real and imaginary parts of the calculated total impedance in $\Omega$. The calculation of the input electrical power density was made for each condition of the applied frequency. Note that, for $\mathrm{N}=1$, the electrical power density of the electrodes $\left(\mathrm{p}_{\mathrm{e}}\left(\mathrm{W} / \mathrm{cm}_{\mathrm{e}}\right)\right)$ is equal to the electrical power density of the actuator $\left(\mathrm{p}_{\mathrm{e}}{ }^{*}\left(\mathrm{~W} / \mathrm{cm}_{\mathrm{a}}\right)\right)$, while for $\mathrm{N}=2$, is the half of it because $\mathrm{L}_{\mathrm{a}}=\mathrm{L}_{\mathrm{e}}$ whatever the ASDBD number of the actuator.

Figure 4 presents the theoretical curves of the electrical power density traced according to the applied frequency for both actuators. It highlights that the electrical power density reaches a maximum at $6 \mathrm{kHz}$ for a single-ASDBD actuator and at $5.4 \mathrm{kHz}$ for a two-ASDBD actuator. These frequency values correspond to the resonance frequencies of the system \{actuator, power supply \} in both cases. The theoretical curve shows that $\mathrm{p}_{\mathrm{e}}$ is equal to $4.6 \mathrm{~W} / \mathrm{cm}_{\mathrm{e}}$ for the singleASDBD at its resonance frequency and to $2.3 \mathrm{~W} / \mathrm{cm}_{\mathrm{e}}$ for the two-ASDBD actuator at its resonance frequency. 


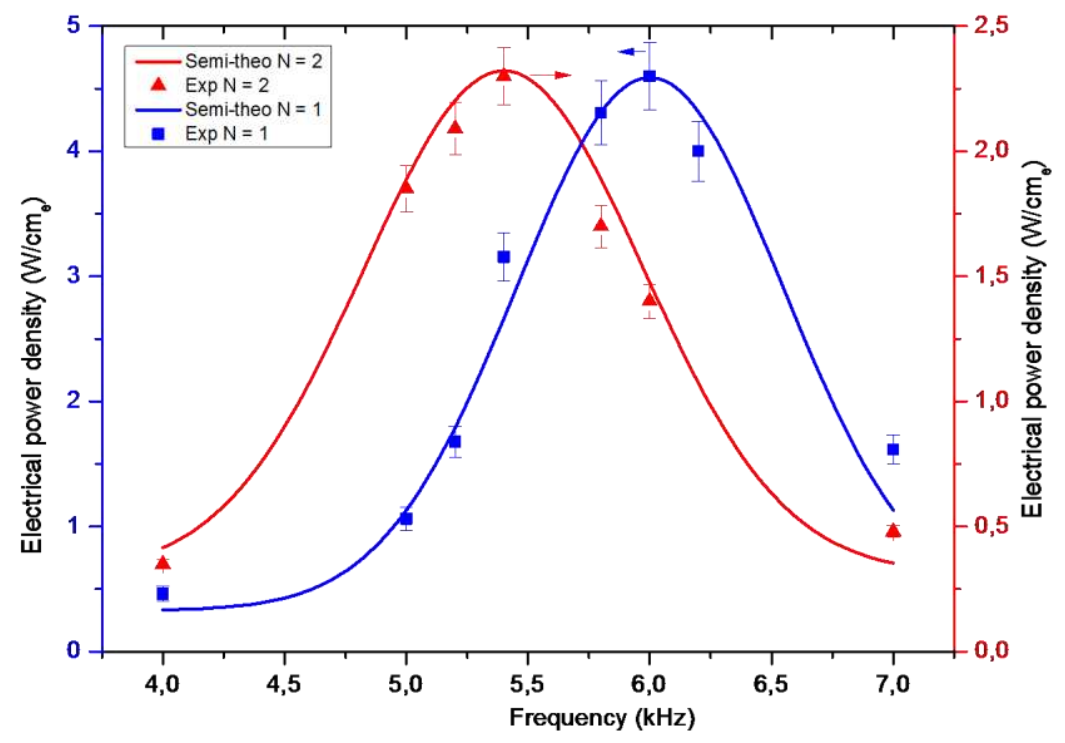

Figure 4. Electrical power versus applied frequency of the single and two-ASDBD actuators: experimental points obtained by measurements and semi-theoretical curves obtained by the coupling between the actuator's impedance calculation and an rms voltage measurement

\section{b. Experimental method}

The electrical power density input to the electrodes was also determined experimentally throughout the recovering of the voltage and current measured at the terminals of the actuator. $P_{e}$ was calculated by taking into account a one signal period as given in the expression (8):

$P_{e}\left(W / c m_{e}\right)=\frac{f}{N \cdot L_{e}} \cdot \int_{t=0}^{t=T} U(t) I(t) d t$

where $f$, $\mathrm{U}(\mathrm{t}), \mathrm{I}(\mathrm{t}), \mathrm{T}, \mathrm{L}_{\mathrm{e}}, \mathrm{N}$ are the applied frequency in $\mathrm{kHz}$, the measured voltage in $\mathrm{kV}$, the discharge current in $\mathrm{mA}$, the period duration in and $\mathrm{L}_{e}$ the electrode length and the ASDBD number of the actuator, respectively. The reproducibility of the electrical energy transferred per signal period was verified in order to confirm its accuracy before using the formula.

The evolution of $P_{e}$, determined experimentally, versus applied frequency for both actuator configurations: single-ASDBD and two-ASDBD, are illustrated in Figure 4. As shown in this figure, the input electrical power density is proportional to the frequency. The experimental power density deduced from electrical measurements has the same evolution as the theoretical curves for a single-ASDBD as well as for the two-ASDBD actuator. The comparison between the theoretical curves and experimental points puts in evidence a slight difference (lower than 5\%) between the corresponding power densities. The similar maxima obtained by both methods led us to confirm the values of the resonance frequencies: $f=f_{0}{ }^{\mathrm{N}=1}=6 \mathrm{kHz}$, for the single-ASDBD actuator and $f=f_{0}{ }^{\mathrm{N}=2}=5.4 \mathrm{kHz}$ for the two-ASDBD one. Moreover, the values of the electrical 
power density input to the electrodes are the same by these two methods. They are equal to: 4.6 $\mathrm{W} / \mathrm{cm}_{\mathrm{e}}$ for the single-ASDBD and $2.3 \mathrm{~W} / \mathrm{cm}_{\mathrm{e}}$ for the two-ASDBD one. Hence, the addition of a second-ASDBD is clearly shifting the resonance frequency toward the lower frequencies. Finally, as it is confirmed in Figure 4, we can say that these two methods of electrical power density determination are in total agreement.

\section{Conclusion and perspectives}

The electrical behaviour of a single-ASDBD actuator and a two-ASDBD actuator were studied in this paper. The electrical behaviour study was focused on the influence of frequency on electrical power density input to the actuators. We determined the electrical power density using two methods, a theoretical method and an experimental one. The first method passed through the calculation of the actuators total impedance by choosing to model the system with a specific electrical equivalent circuit, while the second method was based on direct measurements of voltage and current.

Similar results using both methods confirmed the existence of a resonance frequency, depending on the actuators configuration, which maximizes the input electrical power density to the actuators. With our power supply, the resonance frequency of the single-ASDBD actuator is equal to $f_{0}^{\mathrm{N}=1}=6 \mathrm{kHz}$ and equal to $f_{0}^{N}=2=5.4 \mathrm{kHz}$ for the two-ASDBD actuator. As a conclusion, the resonance frequency is dependent of the number of ASDBD composing the actuator. This work represents a first step toward the design of efficient multi-ASDBD actuators by determining and operating at the system resonance frequency.

\section{Acknowledgments}

The authors gratefully acknowledge CARNOT M.I.N.E.S Institute for their financial supports and the PACA Region for its contribution to PhD fellowships in this subject.

\section{REFERENCES}

[1] Roth JR, Dai X. 2006, Optimization of the aerodynamic plasma actuator as an Electrohydrodynamic (EHD) electrical device, $14^{\text {th }}$ AIAA Aerospace Sciences Meeting and Exhibit, Reno NV, AIAA Paper 2006-1203.

[2] Léger L, Moreau E, Touchard G. 2002, Electrohydrodynamic airflow control along a flat plate by a DC surface corona discharge - velocity profile and wall pressure measurements, AIAA Paper, 2002-2833.

[3] Roth J R. 2003, phys. Plasmas, 10:2117-26.

[4] Borghi C A, Carraro M R, Cristofolini A, et al. 2008, J. Phys. D., 103:063304.

[5] Zito J C, Durscher R J, Soni J, et al. 2012, Appl. Phys. Lett., 100:193502.

[6] Boeuf J P, Lagmich Y, Unfer Th, et al. 2007, J. Phys. D: Appl. Phys., 40:652-662.

[7] Thomas F O, Corke T C, Iqbal M, et al. 2009, AIAA J., 47:2169-78.

[8] Forte M, Jolibois J, Pons J, et al. 2007, Exp Fluids, 43:917-298.

[9] Debien A, Bernard N, Moreau E. 2012, J. Phys. D: Appl. Phys., 45:215201.

[10] Enloe C L, McLaughlin T E, VanDyken R D, et al. 2004, AIAA Journal, 42:595-604.

[11] Pons J, Moreau E, Touchard G, 2005, J. Phys. D. Appl. Phys., 38:3635-3642. 
[12] Kreigseis J, Moller B, Grundman S, et al. 2011, Journal of Electrostatics, 69:302-312.

[13] Enloe C L, McLaughlin T E, VanDyken R D, et al. 2004, AIAA Journal, 42:589-594. 